\title{
Philanthropy from Rumi's View Point
}

\author{
Ahmad Reza Yalameha
}

\begin{abstract}
Social psychology is a science that investigates the mutual behavior of individuals with each other. It also studies the behavior of human kind and analyzes the social behavior that has a cooperation nature. One of the important subjects of this science is philanthropy. Philanthropy as an admirable social behavior has been approved by all human being with any languages, nationality, and trends over time. On the other hand, poetry and Persian literature have been the important manifestations of social subjects and they were full of attention to the philanthropy and peace, saving human life, humanitarianism, peace orientation, avoiding hatred, respecting humanity, dignifying human kind, helping subordinates, calmness, unity and integration and the like that they have relationship with social psychology. One of the greatest thinkers of Persian literature is Rumi. The poetry language of Rumi is in such a way that he has spoken for all nations through the centuries and it is beyond limitation of time and place. He believes that with respect to the commonality of human creation, human existence originated from the same source; therefore, all humans should help each other in case of difficulties. This research paper tries to investigate and analyze human philanthropy as an admirable human behavior in the Mathnavi of Rumi and clarifies the view point of this philosopher with respect to this subject matter.
\end{abstract}

Index Terms-Social psychology, Persian literature, Rumi, philanthropy, the principle of commonality in creation, respecting humanity.

\section{INTRODUCTION}

Social psychology is a science that pursues the causes of behavior, emotions and human thoughts in different social contexts. Some kinds of these social behaviors have supportive or prosocial nature and focus on cooperation as the main quiddity. These behaviors which are known as supportive are manifested through a sense of altruism and because of diversity in human needs; they can be shown in different forms. Sometimes they are shown in the form of emotional support. Moreover, in other cases they are manifested as caress, appeasement, loving speech to others, meeting and visiting relatives, life protector ships or general social support like sympathy, sacrifice, help, and so on.

In fact, altruism as an acceptable social behavior is admired by all human beings in every nation and in different times, irrespective of today's borders.

The concept of altruism and peacefulness can be clearly found in Persian poetry in different forms.

Manuscript received May 23, 2017; revised June 25, 2017.

Ahmad Reza Yalameha is with Persian Language and Literature, Young Researcher and Elite Club, Dehaghan Branch, Dehaghan, Isfahan, Iran (e-mail: ayalameha@dehaghan.ac.ir).

\section{DISCUSSION}

\section{A. Persian Literature and the Notion of Philanthropy}

Today, one of the most elegant expressions in the world literature is the theme of philanthropy or altruism. This human value in most of the world literary works has been reflected in diverse manifestations and thinkers of the world have been analyzed it from different viewpoints [1].

Man because of his own characteristics, is the only creature that cannot achieve perfection without getting the concept of friendship and evasion from himself and his loneliness. Human kind possessing this divine temper will be better able to actuate his latent talents.

If the word of human is thought, it will be found that therein lay the concepts of peace, friendship and love, and one for any reason has the natural tendency to his fellow. So, in various situations regardless of language, culture, race, religion, one hurries up to help and assist other humans or at least has sympathy for them. In other words, it can be said that the human heart beats for everyone, not for specific class of them.

Although human's entity has dimensions and layers and different talents and a set of features and characteristics that nature, reason, emotions, responsibility, artistry, social life are of the most important aspects of his existence, in the human essence, there is a set of emotions and feelings among which love and hatred are the most obvious. If love that is rooted in human nature was issued consciously and voluntarily, and noticed another man, a special effect of affection named humanitarianism or philanthropy would be actuated.

On the other hand, one of the basic needs of every human being is achieving human perfection and absolute perfection. All human efforts are for getting this point of excellence and as long as he did not achieve the culmination, the cry of human need is continuously aloud. So, if a human finds someone or something that partially satisfies his needs for perfection, or that is a vehicle to achieve his sublime goal, he will love it and will be kind to it.

One of these devices is the feeling of friendship and love people and one of the realms in which this pure human thought has been crystallized, is Persian poetry and literature.

Literary works of Persian poets, especially Ferdowsi, Nizami, Attar, Mowlana Rumi, Sa'di, Hafiz and Jami in terms of time in offering subjects like friendship, peace, speciesism, are earlier than the literature of other peoples and nations of the world. Hence, the capacities of Persian literature in promoting this sublime human concept, that is, peace, friendship and altruism should not be disregarded

An approach based on love and humanities is evident all over the Persian poetry and Persian classic works are full of 
sublime concepts such as humanity, altruism, morality, self-esteem, benevolence, honesty people, and goodness.

Also, these works criticize the negative concepts of extremism, violence, hatred, revenge and vengeance and always advise the human beings about controlling their interior and exterior tyranny.

Yes, in the rich Persian culture and literature, concepts of man, human rights and pure human values are of high eminence. The great poems of Persian Language and Literature, from the oldest times, to the contemporary poets, well illustrate this fact.

Committed Persian poets have always believed in and undertaken human, ethical and social rights. Moreover, supporting of liberty, equality, rights of women and children, the right to education, social justice, the right to choose, enjoying relative prosperity and economic justice in Persian literature and poetry are frequently appeared and raised.

One of the effects of manifesting these themes in Persian literature is that Persian literature and poetry is idealistic and raises idealism. Because, the Persian poets have always paid attention to the "should-be" and ideal world and waiting for a better and more prosperous day for human kind.

Once everything is in the satisfaction of the human heart and there are no traces of oppression, suffering, disease, disorder, anguish, smart pain and disappointments. Whatever there is, is hope and long of well-being which is always the basis of human life and stimulation to continue his efforts.

Among the literary works, the attitude of mystics and mystical works toward the sublime concept of altruism is of special importance and suggests that the mystics in this particular ground have a higher concern, because the mystics believe in separating the two, the world and the Hereafter, and consider them as the place of manifestation of one truth.

\section{B. Molawi's Point of View}

One of the great scholars and poets who has manifested this notion is Rumi (1207-1273) [1]. Mathnavi, as one of his masterpieces constitutes the great encyclopedia of Persian language which has covered every rules and regulations about moral behavior. In other words, this book has paved the way for solidarity and alliance among nations.

Studying the Mowlana Rumi's point of view on humans, human rights and notions of altruism and philanthropy, opens new windows to us and his poems always lead us to human unity and the common human perceptions. He always, by using figurative language and stories, has stated effective and interesting speech about the unity of mankind and altruism. Rumi believes that fanaticism is the result of irrationality and rawness and cannot lead the human to achieve his main goal of perfection.

It is for this purpose that Rumi has always encouraged human being, regardless of language, culture, religion and race..., to philanthropy and helping others and empathizing with them. Rumi's overall peace law is the order that governs the universe; the stable order that despite all the destruction and chaos, changes and transformations causes the nature to reach the perfection.

He believes that only peace and seeking it brings tranquility and develops cognition. Peace with the people, in fact, is taking the common denominator between their interests and those of others in the pursuit of the truth; the fact that is behind the screen of physical, mental and emotional borders and different traits in human nature.

Yes, all the Molana asked is wisdom and reaching perfection. He is familiar with all the demands and aspirations of human kind and knows man as the symbol and the sign of absolute perfection.

Rumi's poetry language is in such away as if he has spoken for all nations through the centuries beyond the limitations of time and place. He is familiar with the demands and aspirations of the human beings. He calls for awareness and wisdom so that due to this awareness, nations put their problems away and live in complete peace regardless of the conventions.

He believes that factors like peace and toleration with fellowmen, caring about the weak in the society, avoidance of enmity, ignoring others' slips and wrong-doings, chivalry and forgiveness, overlooking the faults of others, respecting different ideas and other nations' rights, avoiding prejudging, and believing that the whole society should be viewed as a unit, can cause unity and altruism in the society. He also believes that selfishness, as a kind of immoral behavior and the main cause of not tolerating others' beliefs, is the reason for lack of peace and stability in the world:

Since I am incessantly waylaying (struggling with) myself, how should I act in harmony with another?

In his opinion, altruism is that human trait which can make human be unselfish and show sacrifice and forgiveness as well. This feature can also create a friendly and hearty relationship among the individuals in the society. In both Mathnavi and Divan-e shams (his lyric poems), when he wants to show different aspects of peace, he refers to the compatibility and congruency among opposites existing in the universe.

In this respects, he talks about the peace among human beings and peace with God which is the most complete and striking type of peace and reconciliation of opposites in the universe. This reconciliation is the factor for survival of all beings in the universe. This can lead human beings toward the higher world (Heaven) which is the world of unity and divinity. In that world, there is no sign of opposites and paradoxes .There exists only pure honesty. [6].

The main reason for Rumi's tendency toward peace and reconciliation lies in his gnostic (mystic) beliefs. His thoughts were formed under the training of his three main masters who were his father, Bahauddin Termazi and Shamse Tabrizi. Definitely his social context had the major role in the formation of his thoughts.

Rumi's Sufi mysticism was at the heart of society, and this was the reason for his close relationship with different social classes. He had three outstanding personalities that originated from three major scientific and mystical stages in his life .He himself referred to them as the raw ,maturity, and burning stages that led him to the last degree of human perfection.

"Rumi as a Muslim poet and based on his theological views, reminds us that human beings will be rewarded in both this world and the hereafter. Certainly, what they get in the hereafter will be much more than what they get in this world. Therefore, according to this idea, both this world and the 
hereafter are the places for rewarding good and bad human actions. Definitely, altruistic individuals are not the exceptions for this rule and will receive their rewards in both of these world [2].

A highlight of altruism in social psychology is the sense of social responsibility. Norm of social responsibility refers to the belief that a person, regardless of retaliate in kind, helps others and this is the response to the inner call of conscience (Belov,2006) [3]. This notion has a special place in Mathnavi He describes these individuals as people with certain spirits. $\mathrm{He}$ gives them the attribute of brevity or lion heart. $\mathrm{He}$ believes that these people, due to great affection and early fusion that they have, will help others without expectation of rewards:

The valiant (holy) men are a help in the world when the wail of the oppressed reaches (them).

From every quarter they hear the cry of the oppressed and run in that direction, like the mercy of God. (Foruzanfar, 2008: 123) [4]

It should be mentioned that altruism in Rumi's view is not limited to financial, emotional, and life supports. An altruist can show his altruism with providing services and intellectual support. In fact, an altruist cannot be indifferent to others' problems. In other words, he tries to behave in a way that is suitable for that occasion. He has accepted this principle that every individual is originated from the same source and people have similar origination regarding their creations. Considering this fact, color and race difference cannot make people doubt about doing humanitarian and altruistic functions [5].

In other words, these differences cannot affect this sense:

Do not look at his figure and color; look at his purpose and intention.

If he is black, (yet) he is in accord with you: call him white, for (spiritually) his complexion is the same as yours. [7]

If people consider others' problems as their own, it can cause a kind of unity and solidarity in human society. And in that case, people acquire a sense of self-sacrifice thinking. They consider themselves responsible for others' problems and cannot ignore and be indifferent in these kinds of situations. This is the spirit of altruism and loving others:

If you desire tears, have mercy on one who sheds tears; if you desire mercy, show mercy to the weak.

Considering this line of poetry, Kaviani (2010: 115) believes that Rumi gives the impression that if a person is kind to those in need, others will help him in his hard positions. So he recommends that people help each other. Secondly, helping others is considered as a reward because it causes that the person who helps others, will be free from the pain and sorrow of watching these kinds of situations. There are much evidence stating that if a person watches others in pain, he himself will suffer from turmoil and grief. Thirdly, by helping others, human will get another reward which is social approval; that is, an increase in considering himself more valuable.

Mowlana Also has ideas on misunderstanding as the root of wars. Some Principles for achieving a Global Understanding in Rumi's Views are as following:

\section{A. Presenting Learners with Single Values}

Rumi believes that the reason why nations fall and humanity collapses lies in the false methods and teaching them to men. Hence, the modern teaching method breeds aggressive and immature youths. We are all creation of God, with one purpose; therefore, our values can be the same.

\section{B. Spiritual Educating as Well as Practical Educating}

Rumi identifies men as a godlike creature whose reason and intellect is in his control:

A sea of knowledge concealed in a drop

A world concealed in a piece of flesh

Hence, recognition of the spiritual worth of men will never allow the human self- esteem to be undermined by any of the differences in views and schools of thought.

\section{Communicating Thoughts}

He believes that tolerance and coexistence of nations and sects can be fulfilled by communicating thoughts and dialogues instead of prides and prejudices. He was thinking on an international organization:

When souls conjoin each other

The little intellect will diminish

\section{A Compassion-Based Educating}

Rumi is of the belief that love will conquer all tensions; contrary to the reason that inevitably loses, love assists the griever. Hence, breeding or teaching should lead to loving each other, not enmity:

Compassion turns all bitterness to sweet

Compassion turns all steel to gold

This compassion is beget by knowledge

It does not breed off the cough

\section{E. Taking Care of the Family}

Contrary to many Sufis who are negligent of family and society, Rumi keeps a serious look on this respect. Urging to do good things, advising children, paving the way for marriage, etc. could be found in every corner of Rumi's writings: "dear child, know that the unfaithful transient lust is not worth to injure the heart of friends and destroy humanity and chivalry" [8].

\section{F. Washing Superficial Baseless Misinterpretations}

In Rumi's views, if a sage, a mystic to truths and or an enlightened man let people know of these superficial misinterpretations, most of the wars and tensions of the world and men would disappear. He tells the story of four men (an Arab, a Persian, a Turk, and a Greek) in his book, Mathnavi, who went on a tension over one single thing because they did not know the language of each other.

\section{CONCLUSION}

In general, it can be concluded that respecting fellowmen and caring about the others rights are the vital principles and the golden rules of all religion and societies. This sense is at odds with pursuing only self-interest activities, ignoring others rights, and the lack of a common sympathy among people. Altruism is considered as a valuable human concept which recognizes no boundaries and affects ethnicity and race. Altruism and philanthropy are considered as special concepts in the works of Iranian poets. Different aspects of this notion can be found in Iranian poetical works. One of 
works that is Mathnavi. Rumi views altruism as valuable human trait and encourages people in different parts of Mathnavi to have this desirable trait.

Rumi is a great mystic, rather than being a poet, whose insights and practices during his motivational life have been an inspiration for many of frat figures in mysticism and philosophy in the new and old world. One reason why Rumi is attractive lies in his tolerant insights that absorb the people from all cultures and languages in all times. Undoubtedly, the spread of Rumi's names in all corners of the world lies in his high-mindedness and comprehensive look that loved men apart from his formal appearance features. In today's modern world which is equipped with sophisticated technologies beyond our heads, men still needs sources like Rumi for a better life and establishing global peace whereby most tensions would be found to be baseless.

\section{REFERENCES}

[1] E. Arenson et al., Social Psychology, Tehran: Ma VA Shoma Publication, 2005, pp. 49-53.

[2] N. Ayzenburg, Social Behavior of Children, Tehran: Ghoghnoos Publication, 2005, pp. 126-129.

[3] B. N. Mary and N. Odil, Social Psychology, (An Introduction to Theories and Rituals), Tehran: Avaie Noor Publication, 2006, pp. 219-234.
[4] B. Foruzanfar, Sharhe Mathnavi Sharif, Tehran: Zavar Publication, 2008, pp. 81-86.

[5] Y. Karami, Social Psychology, Tehran: Arasbaran Publication, 2001, pp. 263-267.

[6] M. Kaviani and S. S. Mosavi, Psychological Analysis oo Molavi Point of View in the Subject of Philantropy, 2010, pp. 153-159.

[7] M. Jalaldin, Mathnavi, Tehran: Zavar Publication, 1993.

[8] M. Jalaldin, Maktubat (the Letters), Tehran: Academic Center of Publication, pp. 30.

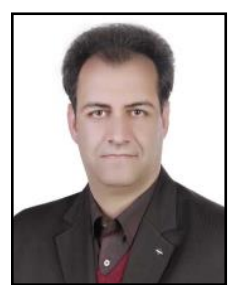

Ahmad Reza Yalameha was born in Iran, Esfahan in 1974; He got his diploma in culture and literature in 1996. Then, in the year of 1992, he succeeded in entering the university of Esfahan for BA in the Persian language and literature. He entered the Esfahan University in 1996 for M.A in the Persian language and literature. At same time he became the first Iranian student in scientific Olympiad of the country in 1998. He succeeded in getting his $\mathrm{Ph} . \mathrm{D}$ from that university in 2004. He is one of the youngest professors in the Persian language and literature. His major specialty focuses on codicology and identification of ancient texts and he registered 27 books and 120 research scientific articles in his valuable work background. Mr. Yalameha, is one of the young researchers who stood at the grade of full professor of this field and he is one of the members of elites and gifted and talented students center of Azad university. 